\title{
A study on the effect of occupational stress on job performance in the nursing staff of a tertiary care teaching hospital in Surendranagar district
} Krupal J Joshi $^{1}$, Kishor Sochaliya ${ }^{2}$, Bhautik Modi ${ }^{3}$, Lokesh Sharma ${ }^{4}$, Snehil Singh ${ }^{5}$, Girija P Kartha ${ }^{6}$

${ }^{1}$ Associate Professor, Department of Community Medicine, C. U. Shah Medical College, Surendranagar, Gujarat; ${ }^{2}$ Professor, Department of Community Medicine, C. U. Shah Medical College, Surendranagar, Gujarat; ${ }^{3}$ Associate Professor, Department of Community Medicine, Dr. N. D. Desai Faculty of Medical Science, Nadiad, Gujarat; ${ }^{4}$ EVM Coordinator, NCCVMRC, National Institute of Health and Family Welfare, New Delhi; ${ }^{5}$ Team Lead - NCCVMRC, National Institute of Health and Family Welfare, New Delhi; ${ }^{6}$ Professor \& Head, Department of Community Medicine, C. U. Shah Medical College, Surendranagar, Gujarat.

\begin{tabular}{|c|c|c|c|c|c|c|c|c|}
\hline Abstract & Introduction & Methodology & Results & Conclusion & References & Citation & \multicolumn{2}{|c|}{ Tables / Figures } \\
\hline \multicolumn{9}{|c|}{ Corresponding Author } \\
\hline \multicolumn{8}{|c|}{$\begin{array}{l}\text { Dr. Krupal J. Joshi, “Aashutosh”, Block 87, Sanjivani Society, Ratanpar, Surendranagar, Gujarat- } \\
363020 \\
\text { E Mail ID: dr.krupaljoshi@gmail.com }\end{array}$} & 回语回 \\
\hline
\end{tabular}

\section{Citation}

Joshi KJ, Sochaliya K, Modi B, Sharma L, Singh S, Kartha GP. A study on the effect of occupational stress on job performance in the nursing staff of a tertiary care teaching hospital in Surendranagar district. Indian J Comm Health. 2021;33(1):139-145. https://doi.org/10.47203/IJCH.2021.v33i01.019

Source of Funding: Nil Conflict of Interest: None declared

\section{Article Cycle}

Received: 22/10/2020; Revision: 15/01/2021; Accepted: 10/03/2021; Published: 31/03/2021

This work is licensed under a Creative Commons Attribution 4.0 International License.

\section{Abstract}

Introduction: Occupational stress is a health hazard to the individual worker both physically and psychologically. Research for the past years shows that, signs of occupational stress appear to be rising amongst nursing profession. The ability of nurses to appropriately handle stress while on duty may have a significant impact on individual outcomes, especially job performance. Objective: This study was conducted to measure the workrelated stress and its association with the job performance among nurses. Methods: A pilot study was done and prevalence of work related stress was $13 \%$ on the basis of which sample size was calculated which was 102 (in open epi). The 102 nurses were selected randomly from a tertiary care teaching hospital of Surendranagar district. The data was collected using a structured self-administered questionnaire which included questionnaires on demographic variables, level of work stress and job performance. Results: The findings of the study revealed that moderate and severe level of work stress was present in $53 \%$ and $45 \%$ of nurses respectively. The mean job stress score was found to be higher among younger nurses than those of more than 40 years. There was a negative relationship between job stress and job performance $(r=-0.01)$ among staff nurses. Conclusion: Based on study findings, it was concluded that all the nurses were suffering from mild to severe level of work stress. and it was negatively correlated with the job performance of the nurses. Hence, it is recommended that corrective measures may be planned by the authority to reduce the work stress of nurses to improve the job performance.

\section{Keywords}

Occupational Stress; Job Performance; Nursing Staff

\section{Introduction}

Work stress is recognized world-wide as a major challenge to workers' health and the healthiness of their organizations. $(1,2)$ Occupational stress is of key interest to employers because of the known adverse effects on employee performance, productivity, job satisfaction and health as a whole. 
The working environment is one of the most important resources of occupational stress. (3) Nurses' environment includes an enclosed atmosphere, odd duty times, pressures related to performance without second chance, excessive noise, sudden swings from intense to mundane tasks, unpleasant sights and sounds and long hours of standing. (4) Though they are trained to deal with these factors. stress can take a toll when there are additional or multiple stressors. Stress is known to cause emotional exhaustion which may lead to negative feelings toward those in their care. (5) Additionally, research has demonstrated that as workload and work-associated stress increase, turnover rates and absenteeism of workers are also noted to increase. This can result inconsiderable costs to organizations in terms of loss of productivity and health care resources. $(6,7,8,9)$

Job performance defined as the effectiveness of a person in carrying out his or her roles and responsibilities related to direct patient care. Many define it as fulfilling the assigned roles and responsibilities effectively. (10) In general, job performance is a multifaceted phenomenon with many variables affecting its level such as individual characteristics, work load, work satisfaction, personal competencies, recognition of achievements, social support, supportive communication and feedback, leadership behaviour and organizational climate. $(11,12)$ Poor job performance as a result of occupational stress and decreased satisfaction is considered a risk factor for patient safety. (13) Several studies showed address a negative linear relationship between occupational stress and job performance. (14)

\section{Aims \& Objectives}

The current study was conducted to determine the level of occupational stress, it's effect on the job performance and to identify the factors related to stress and job satisfaction amongst nursing staff working in a tertiary care teaching hospital of Surendranagar district, Gujarat.

\section{Material \& Methods}

This cross-sectional study was conducted from February 2020 to March 2020. In this study a pilot study was done and prevalence of $13 \%$ was found. on this basis sample size was calculated in open epi software and 102 nurses of tertiary care teaching hospital were selected randomly for participation in the study. Totally 102 nurses who gave verbal consent after orienting them about objectives of the study were included in the study. They were working in eleven different departments of the hospital. They were interviewed and the information was collected through a pre-tested self-administered questionnaire which included

I. Demographic variables like age, sex, annual income

II. Questions related to identification of stress levels and

III. Questions related to the job performance and job satisfaction

A set of 14 questions were selected for selfadministration, to identify the level of occupational stress, which were directly linked to the job and job stress. The Likert Scoring System of 5 points was used for each question viz 1 . Strongly Disagree, 2. Disagree, 3. Neither Disagree nor Agree, 4. Agree and 5. Strongly Agree. The total score of job stress for each nursing staff could be from 14 (lowest score) to 70 (highest score); with a high score indicating more stress. The level of occupational stress was then classified based on the total score obtained by each as: no stress -14 points, mild stress -15 to 32 points, moderate stress -33 to 50 points and severe stress 51-70 points. Another set of 14 questions with response to be answered in Five Point Likert Scale (same as above) was also identified to determine the level of job performance. The higher the score indicating better the job performance.

Ethical permission for the study was obtained from the Institutional Ethical Committee in advance. The Questionnaire was tested for face validity \& content validity and modified accordingly. The tool was checked by introducing the questionnaire to 4 subject experts (One nursing superintendent, two faculties from Psychiatry department and one hospital superintendent) and their inputs were incorporated.

The collected data was then compiled and analyzed using SPSS version 17 . The percentage, mean and standard deviation were computed to describe the demographic variables. To check the relationship between the job stress and job performance, statistical tests like chi square test, correlation coefficient, item analysis, extraction of factors, calculation of internal consistency and crossvalidation. 


\section{Results}

(Figure 1) shows the age wise distribution of the study participants. The sample included a total 102 nursing staff of a tertiary care teaching hospital in Surendranagar. The mean age of the study participants was $29.79 \pm 8.81$ with majority $(64.71 \%)$ belonging to the age group of $20-30$ years. Only $12.74 \%$ of the nurses were in the age group of more than 40 years. Equal number of male and female nurses $(43.14 \%$ \& $56.86 \%$ respectively) were involved in the study.

(Table 1) depicts the distribution of study participants according to their current area of work. Most of the staff were from Pediatrics Department (15.7\%), followed by $14.8 \%$ from General Medicine, $13.8 \%$ from General Surgery, 11.7\% Obstetrics \& Gynaecology, $11.7 \%$ Emergency and $10.8 \%$ from Orthopedic Department.

(Table 2) shows the job stress category among nursing staff . Nearly $98 \%$ of the nurses experienced either moderate $(52.95 \%)$ or severe $(45.09 \%)$ type of job stress. Only $1.96 \%$ experienced mild level of stress.

The mean score of job stress and job performance according to their age is presented in (Table 3). Mean job stress score was 43.21 in the age group of more than 40 years, compared to 51.02 in 20-30 years. As the age increased, the level of job stress decreased. Mean job performance score was highest in more than 40 years of age group compared to younger group. Having more work experience and better understanding about stress generating condition probably helped them to manage their stress.

Mean job stress score as per their current working area (Table 4) revealed a higher level of occupational stress in the nursing staff who worked in department of General Medicine, Emergency, Ophthalmology and Skin compared to Psychiatry, Orthopedics and General Surgery Department.

Exploratory Factor Analysis (EFA) was carried out to identify underlying relationship between the measured variables of the job stress scale. KaiserMeyer-Olkin (KMO) test was first done first to determine the sampling adequacy of the data to be used for factor analysis and Bartlett's test(X2) was used to check the redundancy between variables. The KMO test value in this study was 0.750 , which confirms adequacy of sample to analyze the data based on EFA. While, the value for Bartlett's test of sphericity (X2) was found to be 260.074 with $P=$
0.0001 , indicating an acceptable value to carry out factor analysis subsequently.

(Figure 2) displays the scree plot, which was used to determine the number of factors to be retained in the exploratory factor analysis. The Eigen values $(Y$ axis) are plotted against the corresponding factor ( $X$ axis). A flat line is observed from the third factor onwards indicating that each successive factor accounts for smaller variation in the data.

(Table 5) depicts the factor loadings of the various items for stress scale. It shows that out of the set of 14 questions for stress scale, question no. 1,3,6,7,13 and 14 contributes the highest factor loading value of $0.854,0.850,0.858,0.666,0.808$ and 0.867 respectively. These 6 items collectively account for $68.43 \%$ of the variance and would be considered a strong association for a factor analysis.

The value of KMO test measure obtained for sampling adequacy for performance is 0.79 . This is a 'middling' range for the data to be suitable for Exploratory Factor Analysis. The Bartlett's test result is found to be 536.07 with $P$ value of 0.0001 , indicating sufficient significant correlation in the data for the EFA. Scree Plot for job performance is shown in (Figure 3). In this plot, first 5 principal components have eigen values greater than 1 suggesting the significance of the variables contributing major proportion of variation in the data.

Factor loadings for the job performance scale of nurses are displayed in (Table 6). The results show that item number 2,5,7,9,10 and 12 having strongest association for factor analysis with the factor loading values of $0.877,0.875,0.836,0.768,0.799$ and 0.805 respectively and collectively these 6 items accounts for the $74.52 \%$ of the variance.

Spearman's correlation co-efficient was carried out to determine the relationship between job stress and job performance. The $r$ value obtained was minus 0.01 (negative correlation) with $\mathrm{P}=0.923$, which indicates that as the job stress scale of nurses increased the level of job performance decreased.

\section{Discussion}

The present study was aimed to identify the level of job stress and its effect on their job performance among the nursing staff of a tertiary care teaching hospital in Surendranagar district.

The mean age of the participants was found to be $29.79 \pm 8.81$ years with around two third of the participants belonging to the age group of $20-30$ 

years and $22.55 \%$ to $30-40$ years age group. It was similar to the findings in various other studies. $(15,16,17)$ Males and females $(43.14 \%$ \& $56.86 \%)$ were almost equally distributed. which was also found in other studies. (18)

Amongst the total 102 study participants, majority of the nurses reported moderate to severe stress (52.95\% and $45.09 \%)$. Study conducted on Work Stress Among Nurses in a Private Hospital in Lumajang Indonesia reported low level of stress among $57.5 \%$ followed by 35.5 \& $7 \%$ having moderate to high level of job stress. (19) Nearly similar findings were noted in a study in their survey conducted in 2005 on 314,900 Canadian nurses. (20) Various other studies showed results comparable with this study. $(21,22,23)$

To rule out the underlying relationship of participant's job-related stressor and job stress scale, Exploratory Factor Analysis was carried out. Sampling adequacy for EFA was analyzed using the KMO test and the result was 0.750 , indicating the adequacy of the sample. for EFA. Similar finding (0.740) was also reported by in the study "Exploratory study of factors influencing job-related Stress in Japanese psychiatric nurses". (23) The Bartlett's test of sphericity (X2) in the same study showed significant value of $P(<0.001)$. (24) which was also comparable.

The main purpose of this study was to find out the relationship between the job stress and job performance of the hospital nurses. It was found that the job stress and job performance among the nursing staff was negatively correlated $(r=-0.010)$ with each other. It indicates that as the level of job stress increased in the nurses, their job performance decreased. Similar type of negative correlation between job stress and job performance was observed in various other studies also. $(25,26,27)$ The finding of correlation coefficient was also concurrent with several other studies. $(7,28,29)$

\section{Conclusion}

The present study was carried out to identify the level of occupational stress among nurses and its effect on their job performance. It was observed that all the nurses were suffering from mild to severe level of occupational stress. Mean job stress score was seen to be higher among nurses below 40 years of age and its negative impact was also noted on their job performance. Moreover, a negative correlation also was found between the job stress and job performance score, which clearly indicates that as the level of job stress increases on one scale, performance of work decreases on another scale.

\section{Recommendation}

The study has revealed that maximum stress was experienced by the staff between $20-30$ years of age compared to more than 40 years which has reflected in the performance also.

The new young staff when are recruited can be provided with opportunities and courses for coping up with the stress. Suitable stress managing techniques training should be conducted. This will help the staff to cope up with stressful conditions which in turn can improve their performance.

Improvement in performance and reducing stress can be brought about by including nurses in policy decisions, schedule preparation etc. Repetitive \& non-clinical and non-technical jobs which cause extra burden of work can be reduced. In tertiary level hospitals, stress generates from administrative problems rather than personal and so care should be taken to avoid these causes of stress so that the nursing staff are better motivated to perform better.

\section{Limitation of the study}

Study sample is limited to one hospital only. Study on a large scale could bring about better results.

\section{Relevance of the study}

The findings from the study, highlights the stress levels in the nurses and how they affect the performance. Nursing staff are the main pillars in the health care delivery system. As they are directly involved in the patient care, it is imperative to address the issue of stress and performance level for the welfare of the patients. Understanding the impact and association of the different variables, if hospitals could implement interventions to improve the working environment of their nursing workforce, it could bring about favorable changes.

\section{Authors Contribution}

KJ: Concept, Design \& Definition of Intellectual Content; KJ, KS, BM, LS, SS: Literature Search; KJ, KS: Data Acquisition, Data Analysis \& Statistical Analysis; All Authors: Manuscript Preparation, Manuscript Editing \& Review.

\section{Acknowledgement}

The author is gratefully acknowledged the authorities of the tertiary care teaching hospital where the study was carried out for granting 
permission. We are further indebted to the nursing staff of the hospital who participated in the study and gave their valuable inputs.

\section{References}

1. International Labour Organization. Psychosocial factors at work: Recognition and control. (Internet) Report of the Joint ILO/WHO Committee on Occupational Health Ninth Session Geneva, $1984 . \quad$ Available from: https://www.who.int/occupational health/publications/ILO WHO 1984 report of the joint committee.pdf [accessed on 13 Mar 2021]

2. International Labour Organization. Preventing stress at work: Conditions of Work Digest. Geneva: International Labour office; 1992.

3. Eleni Moustaka, Theodoros C Constantinidis. Sources and effects of Work-related stress in nursing. Health science Journal. 2010;4(4):210-216.

4. Kane PP. Stress causing psychosomatic illness among nurses. Indian J Occup Environ Med. 2009;13(1):28-32. doi: 10.4103/0019-5278.50721. PMID: 20165610; PMCID: PMC2822165.[PubMed]

5. Cottrell S. Occupational stress and job satisfaction in mental health nursing: focused interventions through evidence-based assessment. J Psychiatr Ment Health Nurs. 2001;8(2):157-64. doi: $\quad$ 10.1046/j.1365-2850.2001.00373.x. PMID: 11882121. [PubMed].

6. Nakakis, K., Ouzouni, C. Factors influencing stress and job satisfaction of nurses working in psychiatric units: A research review. Health science Journal. 2008;2(4),183-195.

7. AbuAIRub RF. Job stress, job performance, and social support among hospital nurses. J Nurs Scholarsh. 2004;36(1):73-8. doi: 10.1111/j.1547-5069.2004.04016.x. PMID: 15098422. [PubMed].

8. Gueritault-Chalvin V, Kalichman SC, Demi A, Peterson JL. Workrelated stress and occupational burnout in AIDS caregivers: test of a coping model with nurses providing AIDS care. AIDS Care. 2000;12(2):149-61. doi: 10.1080/09540120050001823. PMID: 10827855. [PubMed].

9. JO Akinboye, DO Akinboye, DA Adeyemo. Coping with Stress in Life and Work place. Ibadan: Stirlin-Hordon Publishers (Nig), Ltd. 2005.

10. Scotter J, Motowidlo S. Interpersonal Facilitation and job dedication as separate facets of contextual performance. Journal of Applied Psychology. 1996;181(5):525-531.

11. Kirkcaldy $B D$, Martin T. Job stress and satisfaction among nurses: individual differences. Stress Med. 2000;16(2):77-89.

12. Sveinsdóttir $H$, Biering $P$, Ramel A. Occupational stress, job satisfaction, and working environment among Icelandic nurses: a cross-sectional questionnaire survey. Int J Nurs Stud. 2006;43(7):875-89. doi: 10.1016/j.ijnurstu.2005.11.002. Epub 2005 Dec 19. PMID: 16360157. [PubMed].

13. Ross Laver. Maclean's The best and worst jobs. Canada: Canada's weekly newsmagazine; 1999. Available from: https://archive.macleans.ca/issue/19990531\#!\&pid=0 1 [accessed on 13 Mar 2021]

14. Verhaeghe R, Vlerick P, De Backer G, Van Maele G, Gemmel P. Recurrent changes in the work environment, job resources and distress among nurses: a comparative cross-sectional survey. Int J Nurs Stud. 2008;45(3):382-92. doi: 10.1016/j.ijnurstu.2006.10.003. Epub 2006 Nov 30. PMID: 17140580. [PubMed].
15. Badil, Hakim Shah, Syed Arif Ali, Muhammad Arsalan Siddiqui. Severity of Stress in Nurses Everyday Life in Karachi, Pakistan. J Liaquat Uni Med Health Sci. 2017;16(1):62-67.

16. Dagget T, Molla A, Belachew T. Job related stress among nurses working in Jimma Zone public hospitals, South West Ethiopia: a cross sectional study. BMC Nurs. 2016;15:39. doi: 10.1186/s12912-016-0158-2. PMID: 27313502; PMCID: PMC4910212.[PubMed]

17. Dr. Tessy Treesa Jose, Dr. Sripathy M. Bhat. A descriptive study on stress and coping of nurses working in selected hospitals of Udupi and Mangalore districts Karnataka, India. IOSR Journal of Nursing and Health Science. 2013;3(1):10-18.

18. K. Vijaya Nirmala, M. Suresh Babu. Job Stress among Health Care Professionals in Selected Hospitals with Special Reference to Age and Gender. International Journal of Science and Research. 2015;4(6):1625-1629.

19. Aryo Dewanto. Work Stress Among Nurses in a Private Hospital in Lumajang Indonesia. KnE Life Sciences. 2018;4(9):172-182.

20. Olofsson B, Bengtsson C, Brink E. Absence of response: a study of nurses' experience of stress in the workplace. J Nurs Manag. 2003;11(5):351-8. doi: 10.1046/j.1365-2834.2003.00384.x. PMID: 12930542.[PubMed]

21. Sagar S., Ravish K. S., Ranganath T. S., Mohammed Tanveer Ahmed, Shanmugapriya D. Professional stress levels among healthcare workers of Nelamangala: a cross sectional study. Int J Community Med Public Health. 2017;4(12):4685-4691

22. Nirmanmoh Bhatia, Jugal Kishore, Tanu Anand, Ram Chander Jiloha. Occupational Stress Amongst Nurses from Two Tertiary Care Hospitals in Delhi Australasian Medical Journal AMJ. 2010;3(11):731-738

23. Nabirye RC, Brown KC, Pryor ER, Maples EH. Occupational stress, job satisfaction and job performance among hospital nurses in Kampala, Uganda. J Nurs Manag. 2011;19(6):760-8. doi: 10.1111/j.1365-2834.2011.01240.x. Epub 2011 Jul 8. PMID: 21899629.[PubMed].

24. Yada $H$, Lu X, Omori $H, A$ be $H$, Matsuo $H$, Ishida $Y$, Katoh $T$. Exploratory study of factors influencing job-related stress in Japanese psychiatric nurses. Nurs Res Pract. 2015;2015:805162. doi: 10.1155/2015/805162. Epub 2015 Apr 2. PMID: 25922763; PMCID: PMC4398950.[PubMed]

25. Ivancevich M.J., \& Donnelly H. J. Relation of Organizational Structure to Job Satisfaction, Anxiety-Stress, and Performance. Administrative Science Quarterly. 1975;20(2):272-280.

26. Stamper CL, Johlke MC. The Impact of Perceived Organizational Support on the Relationship Between Boundary Spanner Role Stress and Work Outcomes. Journal of Management. 2003;29(4):569-588.

27. Usman Bashir, Muhammad Ismail Ramay. Impact of Stress on Employees Job Performance: A Study on the Banking Sector of Pakistan. International Journal of Marketing Studies. 2010;2(1):122-126.

28. Haybatollahi SM. Work stress in the nursing profession: An evaluation of organization causal attribution. Helsinki: Department of Social Psychology, University of Helsinki; 2009. Available

from: https://core.ac.uk/download/pdf/14918825.pdf [accessed on 13 Mar 2021]

29. Maharlouei N, Moalaee M, Ajdari S, Zarei M, Lankarani KB. Caesarean delivery in south-western Iran: trends and determinants in a community-based survey. Med Princ Pract. 2013;22(2):184-8. doi: 10.1159/000341762. Epub 2012 Aug 22. PMID: 22922349; PMCID: PMC5586814.[PubMed]. 


\section{Tables}

\begin{tabular}{|c|c|c|}
\hline TABLE 1 DISTRIBUTION OF STUDY PARTICIPANTS ACCORDING TO THEIR AREA OF WORK( & $\begin{array}{c}\text { W }=102) \\
\text { Pumber }\end{array}$ \\
\hline Department & 15 & 14.8 \\
\hline General Medicine & 14 & 13.8 \\
\hline General Surgery & 16 & 15.7 \\
\hline Paediatrics & 12 & 11.7 \\
\hline Obstetrics \&Gynaecology & 11 & 10.8 \\
\hline Orthopaedics & 12 & 11.7 \\
\hline Emergency Dept. & 7 & 6.9 \\
\hline ENT & 5 & 4.9 \\
\hline Ophthalmology & 3 & 2.9 \\
\hline Psychiatry & 2 & 1.9 \\
\hline Skin and VD & 5 & 4.9 \\
\hline
\end{tabular}

TABLE 2 DISTRIBUTION OF STUDY PARTICIPANTS ACCORDING TO THEIR LEVEL OF STRESS (N = 102)

\begin{tabular}{|c|c|c|c|}
\hline Score Range & Stress Category & Number & Percentage \\
\hline 14 & No Stress & 0 & 0 \\
\hline $15-32$ & Mild Stress & 2 & 1.96 \\
\hline $33-50$ & Moderate Stress & 54 & 52.95 \\
\hline $51-70$ & Severe Stress & 46 & 45.09 \\
\hline
\end{tabular}

\begin{tabular}{|c|cc|c|}
\hline $\begin{array}{c}\text { TABLE } 3 \text { MEAN SCORE OF JOB STRESS AND JOB PERFORMANCE ACCORDING TO AGE(N = 102) } \\
\text { Age }\end{array}$ & $\begin{array}{c}\text { Job Stress } \\
\text { (Mean Score) }\end{array}$ & $\begin{array}{c}\text { Chi Square } \\
\text { (P value) }\end{array}$ \\
\hline $20-30$ & 51.02 & 63.41 & 0.644 \\
\hline $30-40$ & 46.43 & 61.96 & $(p=<0.05)$ \\
\hline$\geq 40$ & 43.21 & 66.2 & \\
\hline
\end{tabular}

\begin{tabular}{|l|c|}
\hline TABLE 4 MEAN SCORE OF JOB STRESS ACCORDING TO AREA OF WORK (N = 102) \\
\begin{tabular}{|c|} 
Department \\
Job Stress \\
(Mean Score)
\end{tabular} \\
\hline General Medicine & 56.4 \\
\hline Emergency Dept. & 55.25 \\
\hline Ophthalmology & 51.8 \\
\hline Skin and VD & 51.5 \\
\hline ENT & 50.43 \\
\hline Pulmonary Medicine & 47.6 \\
\hline Paediatrics & 46.75 \\
\hline Obstetrics \&Gynaecology & 46.75 \\
\hline Psychiatry & 45.33 \\
\hline Orthopaedics & 44.27 \\
\hline General Surgery & 44.21 \\
\hline
\end{tabular}

\section{TABLE 5 FACTOR LOADINGS FOR FACTOR ANALYSIS OF STRESS SCALE}

\begin{tabular}{|c|c|l|c|}
\hline Sr. No. & Q. No & \multicolumn{1}{c}{ Factor } & Factor Loading \\
\hline $\mathbf{1}$ & 1 & I get when I have to work with time deadlines & 0.854 \\
\hline $\mathbf{2}$ & 6 & My senior staff supports me in my work & 0.858 \\
\hline $\mathbf{3}$ & 3 & There is change in the work load on day to day basis & 0.85 \\
\hline $\mathbf{4}$ & 14 & I am pressurized to work overtime. & 0.867 \\
\hline $\mathbf{5}$ & 13 & I get help and support I need from colleagues & 0.808 \\
\hline $\mathbf{6}$ & 7 & I receive feedback of my work only when my work is not satisfactory & 0.666 \\
\hline
\end{tabular}




\begin{tabular}{|c|c|c|c|}
\hline Sr. No. & Q. No & Factor & Factor Loading \\
\hline 1 & 12 & Develop innovative methods and materials for teaching patients & 0.805 \\
\hline 2 & 2 & Coordinate the plan of nursing care with the medical plan of care. & 0.877 \\
\hline 3 & 10 & $\begin{array}{l}\text { Perform technical procedures: e.g. oral suctioning, tracheostomy care, IV therapy, } \\
\text { catheter care, dressing changes. }\end{array}$ & 0.799 \\
\hline 4 & 7 & Promote the inclusion of patient's decision and desires concerning his/her care. & 0.836 \\
\hline 5 & 9 & Initiate planning and evaluation of nursing care with others & 0.768 \\
\hline 6 & 5 & $\begin{array}{l}\text { Identify and include in nursing care plans anticipated changes in patient's } \\
\text { conditions }\end{array}$ & 0.875 \\
\hline
\end{tabular}

\section{Figures}

FIGURE 1 DISTRIBUTION OF STUDY PARTICIPANTS ACCORDING TO THEIR AGE (N = 102)

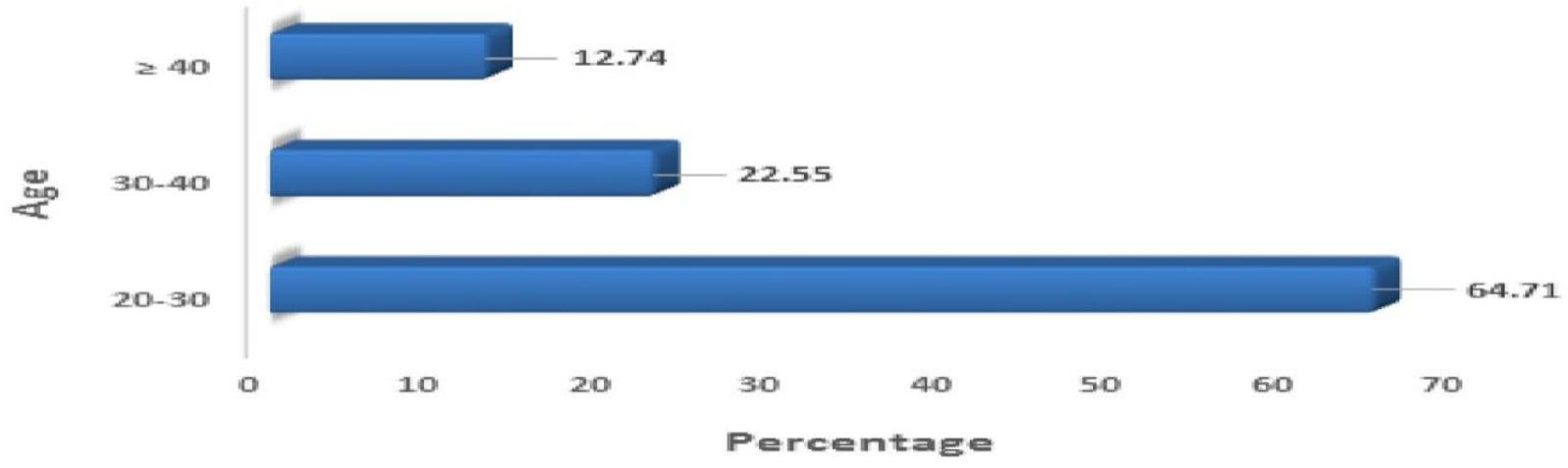

\section{FIGURE 2 SCREE PLOT FOR JOB STRESS}

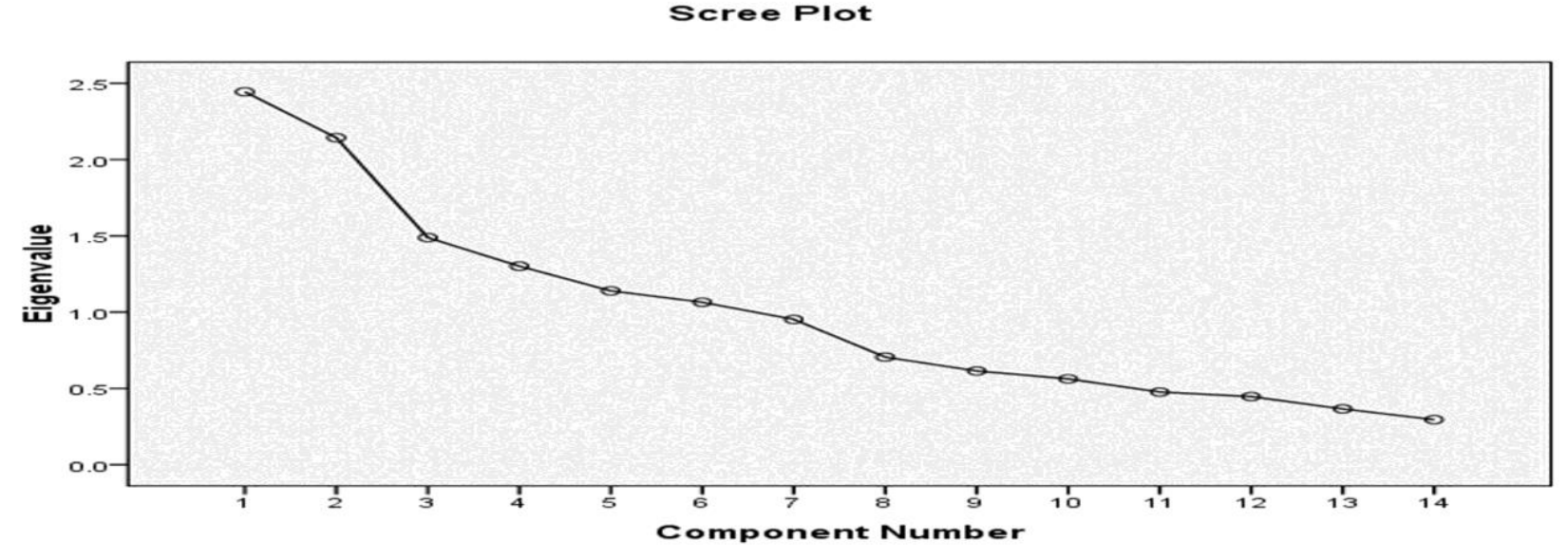

\section{FIGURE 3 SCREE PLOT FOR JOB PERFORMANCE}

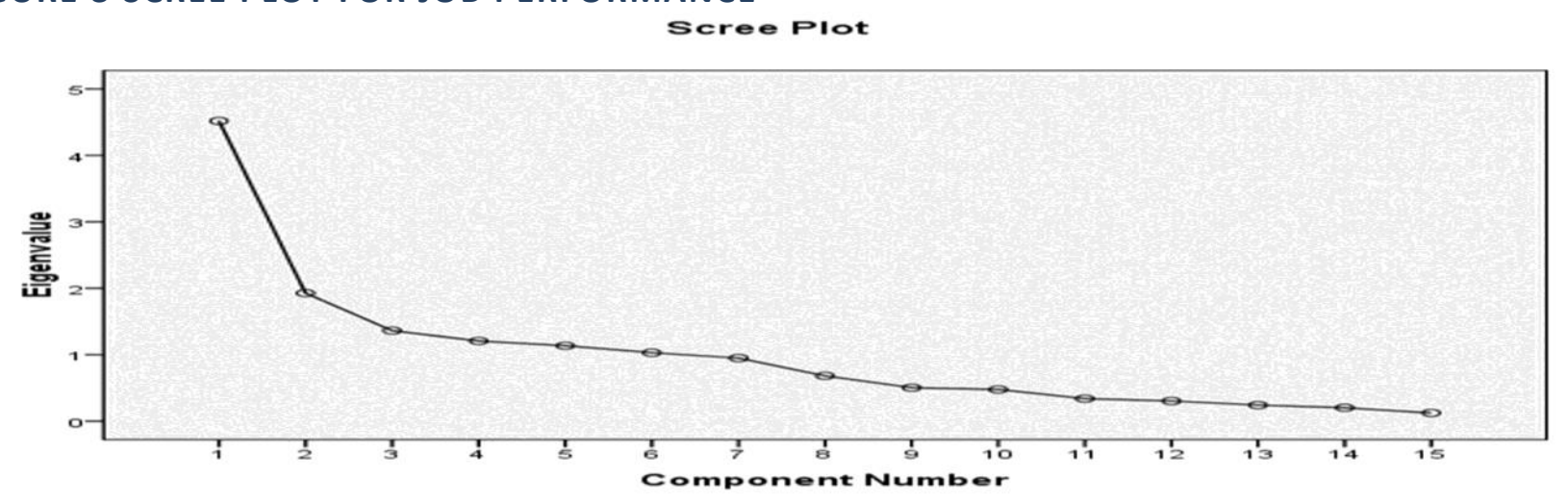

